\title{
Effects of Creative Dispositions on the Design of Lessons
}

\author{
Ulrike Hanke*, Dirk Ifenthaler and Norbert M. Seel
}

Department of Educational Science, University of Freiburg, Germany

\begin{abstract}
Since Skinner's distinction between the science of learning and the art of teaching, it is an unanswered question whether the ability to teach and to plan lessons is based on learning by advice or on special dispositions of the teachers. We therefore addressed the question whether a creative disposition of instructional design students has effects on their designs of lessons. We conducted a study with 44 students. Every student had to design two different lessons which were analyzed in regard to their creativity. Creative lesson designs were defined as innovative being practicable at the same time, and as structurally varied. The results do not provide clear evidence that more creative persons are able to design more innovative lessons that are practicable at the same time. Nevertheless an in-depth analysis shows that more creative participants design more varied lessons.
\end{abstract}

Keywords: Creativity, teaching, instruction, instructional planning, lesson planning, instructional design.

\section{INTRODUCTION}

Since Skinner's distinction between the science of learning and the art of teaching in the 1950s we can observe a significant improvement in the area of learning theories, whereas there is still a substantial lack in the development of theories of teaching and instruction. For this reason, it is still not clear how and based on what conditions teachers plan their lessons and act in the classroom: Do teachers plan their lessons and act in the classroom as a result of learning or as a result of their disposition? According to Skinner [1], who characterizes teaching as an art, the answer to this question may be that the teacher's way of planning and acting in the classroom is a result of his or her disposition. The question is then: What disposition characterizes a good teacher?

As lesson planning is characterized as a problem solving process [2] and if problem solving is considered as a creative process [3-5], then one of the dispositions that characterizes a good teacher may be creativity. As instructional designers like teachers rely more on their practical experiences than on empirical evidence [6], our study investigates whether creative instructional designers really plan better lessons. The first section highlights the respects in which creative persons are different from less creative persons, how creativity may influence the process of planning lessons, and what characterizes a creative way of planning lessons. The next section presents a design experiment used to explore the influence of creativity in planning lessons. Then we present the results from our initial study, before concluding with a discussion of our results and a presentation of future implications.

\section{CREATIVITY}

Research on creativity often has three directions of impact: the creative product, the creative process, and the

*Address correspondence to this author at the Department of Educational Science, University of Freiburg, D-79085 Freiburg, Germany; Tel: +49 761203 9811; Fax: +49 761203 2458;

E-mail: ulrike.hanke@ezw.uni-freiburg.de creative person $[4-5,7]$. The creative product is in some descriptions characterized by two aspects [4, 7-10]: It is new, i.e., different from already existing products, and it is also usable, practical, and helpful.

Creative products may be seen as the result of a creative process that can be characterized as a problem solving process [3-5]. This characterization may seem astonishing, but it is important to emphasize that creativity can be understood as a basic part of thinking and that the creative process in this sense is not an unusual process that is reserved for creative persons, but is rather a usual, everyday process. Thinking that results in creative products is called divergent and may be characterized as free, unsystematic and visionary, and not logically reconstructable [8]. In divergent thinking, existing bits of knowledge are transformed into new combinations through the association of new elements. If this process of transforming, combining, arranging, rearranging, and associating is successful, it results in creative products [3].

Taking into account that we understand creative products as new and useful and created by a divergent way of thinking in a problem solving process, a creative person may be characterized as a person who is able to think in a divergent way and to create new and useful products. Additionally, most creative persons are able to create not only one solution for a problem, but several. Therefore, creativity can be defined qualitatively and quantitatively: Creative persons are able to create a lot of new (quantitative aspect) and useful (qualitative aspect) products [8].

It is evident that the existence of knowledge can support such a creative process, but it is important to emphasize that it does not cause it. The more knowledge is available, the less auxiliary means are needed in order to come to a solution to a problem. But knowledge alone is not sufficient in order to find a solution. On the other hand, if less knowledge is available, an environment that supports creativity or a creative disposition can support the problem solving process [3]. 
In summary, it can be said that persons with a creative disposition may be able to think divergently and may be able to create more new and useful products than less creative persons.

\section{CREATIVITY AND THE PROCESS OF DESIGNING LESSONS}

A differentiation can be made between three different lesson planning strategies: a step-by-step procedure [11], a so-called opportunistic procedure [2, 12, 13], and a procedure following models on how learning environments should be planned, e.g., ADDIE (analysis, design, development, implementation, evaluation; [14]).

The step-by-step procedure is characterized by a sequence of decisions made by the teachers, with every decision resulting in a planned step of the teaching plan [11]. The teachers typically make these decisions not by thinking about various alternatives but by fixing the first idea they have that seems to be applicable. In order to generate these ideas they often use textbooks and curricula, but they hardly take into account intentions or educational objectives at all.

In detail, the step-by-step procedure can be modeled as a process that is mainly driven by scripts and schemata, i.e., it is a top-down process. The starting point of this process is that the teacher represents the work assignment mentally. This representation almost automatically activates a script about the course of action in class, which functions as a blueprint for planning. The individual positions of this blueprint then activate schemata of adequate teaching methods step by step in an ordered sequence. If the activation of an adequate schema fails, a mental model of a teaching method has to be constructed. Regardless of the way in which the teachers have generated the teaching method (by activating a schema or by constructing a mental model), they have to decide whether this method is adequate or not. If they decide that it is adquate, they fix this teaching method and go on to try to activate a new schema in order to specify the next position of the script or construct a mental model if this fails. In this way, every position of the script is specified step by step. This script- and schema-driven stepby-step procedure is shown in Fig. (1).

The opportunistic procedure starts when the activation of a script fails, i.e., it is a kind of fall-back procedure. Like the step-by-step procedure it is activated automatically.

In contrast to the step-by-step procedure, the opportunistic procedure is hardly structured and is characterized by divergent thinking [13]. Teachers generate ideas in an unstructured way, reject some of them later on, and generate other new ideas. They do not fix their first ideas, but arrange them provisionally and rearrange them later on $[2,12]$. This procedure can be described as a process of generating ideas, rejecting some of them, generating new ideas, and arranging and rearranging them. This means that it is not script-driven but can instead be characterized as a model-building process [15] with the lesson design as the resulting model, which is in most parts not fixed before it is completely finished. During this process divergent thinking takes place.

While both the step-by-step procedure and the opportunistic procedure are activated automatically, we assume that the use of a planning model like ADDIE [14] is based on an active decision and normally starts with analyzation of the situation. It is the characteristic of planning models that they emphasize a kind of analysis of the situation before the main planning process begins. In the ADDIE model this process is even called analysis; in other models it is known as didactic analysis [16]. During this process teachers are supposed to think about the conditions of their learners and the situation and to set educational goals.

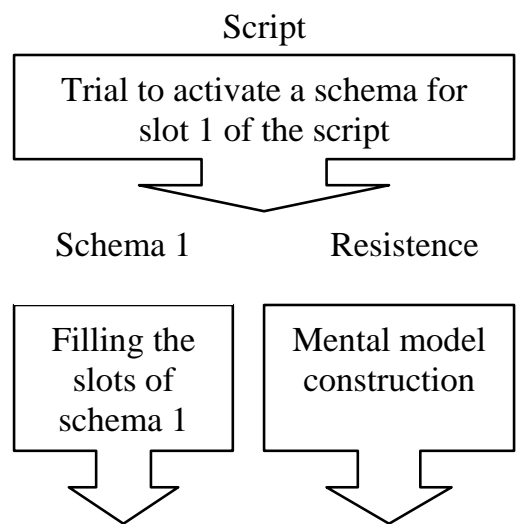

Method 1

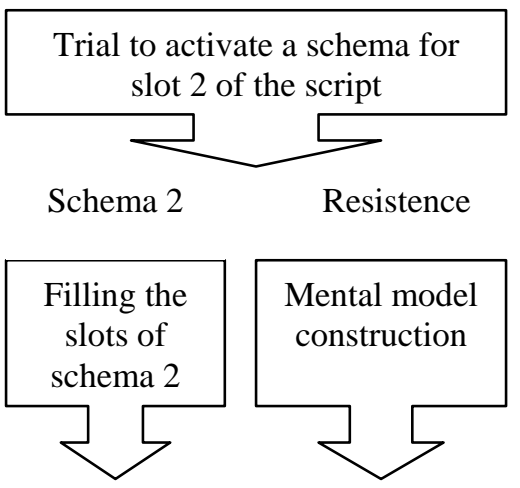

Method 2

Fig. (1). Script- and schema-driven step-by-step procedure.

In detail, the procedure for following a planning model is characterized by an additional process not included in the other two planning procedures presented in this paper. This is the process of actively constructing a model of the situation and using it to gain awareness of the situation. While the two other procedures are characterized by the activation of scripts and schemata or the construction of mental models and do not specify the requirements of the work assignment in detail, the procedure of planning with a planning model may be characterized by the construction of a more detailed representation/model of the situation, the requirements, and the work assignment preceding the real planning process. Even if the real planning process is then script- and schema-driven like the step-by-step procedure, it may be assumed that this situational awareness is the condition for more adequate lesson designs, because when the activation of scripts and schemata is based only on a rough representation of the work assignment, it is evident that there will be more inadequate decisions than when the situation is analyzed in more detail beforehand. 
There is clear evidence for the step-by-step and the opportunistic procedure, whereas there is no evidence that teachers plan their lessons following a model of planning like the ADDIE model [e.g. 2, 11, 12]. This is amazing because it is assumed that these models are taught in every teacher training course. A possible reason why this procedure is rarely used by teachers is that the other two procedures are much more intuitive. First of all, the step-bystep procedure is caused by the teacher's experience. All teachers have already attended many lessons as learners, and it may thus be assumed that they have very stable scripts and schemata on how lessons are structured. They therefore activate these scripts and schemata automatically without reflexion, and as long as this process is automatically initiated and does not fail, they will plan along the lines of a step-by-step procedure. The only opportunity for stopping this process is to become aware of it and to actively decide not to plan in this way. Additionally, this process is automatically interrupted when the activation of a script as a blueprint for the design of the lesson fails. It is supposed that in this case teachers switch from the step-by-step procedure to the opportunistic procedure. This failure therefore has the same effect as becoming aware of the process.

\section{RESEARCH QUESTIONS AND HYPOTHESES}

Every planning process, regardless of whether teachers use it automatically or intentionally, is influenced by the internal conditions of the teacher engaged in it. We assume that depending on their knowledge structure [17-23], their beliefs [24-29], and their motives [30-31], teachers will activate different scripts, make different decisions, construct different models, and use different planning procedures.

Another internal condition that may be related to the planning process is creativity. According to our theoretical assumptions, creativity has to do with the ability to generate new and useful ideas and is therefore highly related to problem solving processes. As the opportunistic procedure of planning is a problem solving process as well and is supported by divergent thinking, we assume that creativity is closely related to this procedure. As a consequence, a creative person should be more successful in planning a lesson when using the opportunistic procedure than a less creative person who uses this procedure. Defining creativity as the ability to find new connections and to put things together in order to come up with new but useful creations, this research study is guided by the following hypotheses: We assume that when using the opportunistic procedure to design lessons, more creative persons are able to design more creative lessons with regard to quality, i.e., their lessons show a higher degree of innovation, and use a higher number of standard and creative teaching methods that are at the same time practicable (hypothesis 1). Additionally, we assume that when using the opportunistic procedure to design lessons, more creative persons are able to design more creative lessons with regard to quantitiy, i.e., they are able to design structurally more varied lessons despite similar conditions (hypothesis 2).

\section{METHOD}

\section{Participants}

The design experiment was conducted with 44 students from the University of Freiburg (29 female and 15 male). They studied Instructional Design as their major field. Their mean age was 22.9 years $(S D=2.61)$. Their participation in the study was a course requirement. Nevertheless, the study was implemented in a way that it was not possible for the lecturer to reconstruct which test belonged to which student.

\section{Materials}

\section{Lesson Design Tasks (LDT)}

Two analogous lesson design tasks (LDT1 and LDT2) were created in order to make sure that the differences between the resulting designs could mainly be interpreted as the result of a creative disposition of the planning person and not by the different requirements of the given conditions. The conditions therefore only differed in the learning objectives.

For the first lesson design task (LDT1), the following learning objective was required: the students must name at least five different evaluation instruments and their advantages and disadvantages without help.

For the second lesson design task (LDT2), the following learning objective was required: the students must name at least five different teaching methods and possible applications without help.

Overall, both lesson design tasks included the following conditions and requirements:

- 25 undergraduate students in Instructional Design (first semester);

- $\quad$ Classroom with movable chairs and desks;

- Various media available;

- Available time in class: 45 min.

As a creative disposition is supposed to be related only to an opportunistic procedure, the participants were explicitly asked to be creative in designing the two lessons and to not design standard lessons. In order to make sure that they did not forget this requirement, the investigator reminded the participants several times and wrote a reminder to be creative on the worksheet with the lesson design task and on the blackboard in the classroom.

\section{Creativity Test}

The German language-based creativity test V-K-T (Verbaler Kreativitäts-Test [32]) was used to classify the participants' creativity. The V-K-T consists of nine subtests which are combined to form a global creativity value. Completing the test takes 47 minutes. Overall, high reliability scores (parallel-test reliability, $r=.91$; test-retest reliability, $r=.85$ ) are reported for the $\mathrm{V}-\mathrm{K}-\mathrm{T}$.

\section{Creativity of Lesson Designs (CLD)}

The creativity of lesson designs instrument (CLD) classifies the degree of creativity of lesson designs. CLD assesses the structural similarity (lesson phase, teaching methods, class arrangement) between two lesson designs created by a single person and the degree of innovation of the design and its practicability.

CLD consists of three dimensions: lesson phase, class arrangement, and teaching method. The lesson phase dimension describes the function of the phases of the lesson. It is separated into a beginning, working phase, and final 
phase. The class arrangement dimension describes how students and teachers interact in this phase. Specifications of this dimension are therefore "plenum," "groupwork," "pairwork," and "individual work." The teaching methods dimension differentiates between methods with low student activity levels that structure the lesson ("presentational methods") and methods with higher student activity levels ("elaboration methods" and "exploratory methods"). The differentiation between these two subdimensions is that elaboration methods structure the lesson more than "exploratory methods" [33]. The instrument is designed in such a way that for every phase one horizonal row is used. In this way, it is possible to analyze the design (interaction of the different specifications) of each phase. Vertically, it is possible to compare the design of the different phases of the whole lesson [33].

Additionally, CLD includes two scales which evaluate the degree of innovation and practicability: The degree of innovation was rated on two items (The design is a typical design for university courses; This is an untypical design), practicability on three items (The design is adapted to the conditions; The design is instrumental; The time management is adequate). All items were rated on a fourpoint Likert scale $(1=$ totally disagree; $2=$ disagree; $3=$ agree; 4 = totally agree).

We performed an interrater reliability analysis using the Kappa statistic [34, 35] to determine consistency among raters for the dimensions of the CLD instrument. Two independent raters found substantial agreement; interrater reliability of $\kappa=.70(95 \% C I[.612, .788], \mathrm{p}<.001)$. Additionally, acceptable internal consistency reliability was found for the scales innovation (Crobnach's alpha $=.92$ ) and practicability (Cronbach's alpha $=.60$ ). Furthermore, a pilot version of the instrument has already been successfully used in a previous research study [33].

\section{Procedure}

In the first phase of the design experiment the participants completed a demographic data questionnaire (3 minutes) and the V-K-T creativity test (47 minutes). Afterwards they were asked to design two analogous lessons (the required duration of each lesson was 45 minutes). The participants had 15 minutes time to design each of the two lessons. After the design phase, the participants received individual feedback on their designs from the course instructor.

\section{Scoring}

For each participant, a global creativity value for the V$\mathrm{K}-\mathrm{T}$ was determined. We operationalized the degree of creativity in the resulting lesson designs in two ways using the CLD instrument: On the one hand we evaluated the lesson designs with regard to their degree of innovation and their practicability in order to obtain information about the qualitative aspect of creative lesson designs, and on the other hand we compared the two designs each student made in order to obtain information about the quantitative aspect of creative lesson designs. Additionally, the number of standard (e.g., teacher-centered teaching, discussion, groupwork, etc.) and creative (e.g., case study, experiments, field trip, role play, etc.) teaching mehtods was determined for each planned lesson. Further, the overall number of didactic steps of a planned lesson was counted.

\section{RESULTS}

Initial data checks showed that the distributions satisfied the assumptions underlying the analysis procedures. All effects were assessed at the .05 level. Main effects of gender were not significant for any measure. Participants could score between 70 and 130 points on the creativity test (V-K$\mathrm{T})$. They scored $M=102.08$ points $(S D=10.345$; Max $=$ $122 ;$ Min $=78$ ). The average number of didactic steps of a planned lesson was $M=5.32(S D=1.01)$ for LDT1 and $M=$ $5.25(S D=1.04)$ for LDT2. Accordingly, the average number of steps correlated significantly between the two lesson design tasks (LDT1, LDT2), $r=.479, p<.001$.

To test the first hypothesis, we divided the data from the creativity test (V-K-T) into high (upper quartile) and low (lower quartile) creativity groups. First, we conducted two independent samples t-tests to compare the number of didactic steps in the high and low creativity groups for the two lesson design tasks (LDT1, LDT2). There was a significant difference between the scores for high $(M=5.64$, $S D=.674)$ and low creativity $(M=4.90, S D=.876)$ groups for LDT1; $t(19)=2.171, p=.043, d=.95$. However, no significant difference was found between high $(M=5.55, S D$ $=1.21)$ and low $(M=5.10, S D=.738)$ creativity groups for LDT2; $t(19)=.328, p=n . s$. Second, we conducted four independent samples t-tests to compare the CLD scale innovation and practicability in the high and low creativity groups for the two lesson design tasks (LDT1, LDT2). No significant difference for the CLD scale innovation between participants in the high and low creativity goups was found for LDT1, $t(19)=.101, n . s .$, or LDT2, $t(19)=.046$, n.s. Also, no significant differences for the CLD scale practicability between participants in the high and low creativity goups were found for LDT2, $t(19)=.063$, n.s., or LDT2, $t(19)=$ .309 , n.s. Last, we conducted six independent samples t-tests to compare the number of standard, creative, and overall teaching methods in the high and low creativity groups for the two lesson design tasks (LDT1, LDT2). There was a significant difference in the number of standard teaching methods for high $(M=4.73, S D=.786)$ and low creativity $(M=3.80, S D=.919)$ groups for LDT1; $t(19)=2.492, p=$ $.022, d=1.09$. However, no significant difference was found between the high and low creativity groups for the number of creative teaching methods for LDT1; $t(19)=.275$, n.s. Nevertheless, there was a significant difference in the number of overall teaching methods for high $(M=5.64, S D$ $=.674)$ and low creativity $(M=4.80, S D=.789)$ groups for LDT1; $t(19)=2.620, p=.017, d=1.15$. For the LDT2, no significant differences were found between high and low creativity groups for the number of standard teaching methods, $t(19)=1.003$, n.s., for the creative teaching methods, $t(19)=.067$, n.s, or for the number of overall teaching methods, $t(19)=1.049$, n.s. Accordingly, the data shows no clear evidence for accepting hypothesis 1, except for the number of didactic steps (LDT1), the number of standard teaching methods (LDT1), and the number of overall teaching methods used (LDT1).

Regarding the second hypothesis, an in-depth qualitative analysis of the differences in teaching methods supports the 
assumption that persons in the higher creativity group used a higher variation of teaching methods in their lesson design tasks (LDT1, LDT2) than persons in the lower creativiy group. Participant E067N (high creativity group) used five standard methods and one creative method in LDT1 and four standard methods and two creative methdos in LDT2. In contrast, participant CG3E (low creativity group) implemented four standard methods in LDT1 and three standard methods in LDT2, however, she did not use any creative methods in both lesson design tasks.

\section{DISCUSSION}

This study examined the influence of creativity on instructional planning. As lesson planning can be characterized as a problem solving process [2] and problem solving is a creative process $[3,4]$, one of the dispositions that characterizes a good instructional designer/teacher may be creativity. We conducted the study described in this paper in order to test the hypotheses that more creative persons are able to design more innovative lessons using more different methods that are nevertheless practical (hypothesis 1) and that they are able to design more different lessons than less creative persons (hypothesis 2).

As the results show, it was not possible to find clear evidence for the hypothesis (1) that more creative persons are able to plan more innovative lessons using more different methods that are nevertheless practical. The only differences we found between the group with higher scores on the creativity test and the group with lower scores was in the number of didactic steps, the number of standard methods, and the number of all methods used in the first lesson design task (LDT1). As these differences were not present in the second lesson design task (LDT2), and as there was no evidence for differences in innovation and practicability of the lesson designs between the two groups in either of the lesson design tasks, the results of this study do not provide evidence for accepting the hypothesis. I.e., according to the results of this study there seems to be no difference between more or less creative persons in their ability to design more innovative lessons using more different methods that are nevertheless practical.

This result may be explained in different ways. One explanation (1) may be that a creative disposition is not a precondition for designing innovative, multifaceted, and practical lessons. As designing lessons can be described as a problem solving process [2] when an opportunistic procedure is used, and problem solving processes are creative processes $[3,4]$, this does not seem to be an adequate explanation, as long as we assume that the participants used the opportunistic procedure.

That the participants did not use the opportunistic procedure may, on the other hand, be an explanation (2). As we tried to encourage the use of the opportunistic procedure only by explicitly asking the participants to be creative in planning, it is probable that this may not have been enough to motivate them to use the opportunistic procedure, because we assume that the opportunistic procedure is only the fallback procedure for the script- and schema-driven step-bystep procedure, which is used as long as there is no reason to not do so. And as was explained above, the use of the stepby-step procedure would not result in differences between more or less creative persons. Therefore, the failure to get the students to use an opportunistic planning procedure may be a good explanation of the presented results.

This explanation becomes even more probable when one takes into account the small amount of time available to design the lessons (15 min. for each lesson design). Because of this time pressure the participants may have had the impression that the use of the opportunistic procedure would not lead to success, i.e., in the form of a complete lesson design. Furthermore, we assume that the participants were not highly motivated to plan the lessons. An indication for this was the fact that most of them even finished their lesson designs in $10 \mathrm{~min}$. although they had $15 \mathrm{~min}$. This missing motivation may also have caused the participants to avoid the use of the opportunistic procedure, because the step-bystep procedure is the more usual and "easier" procedure, as it produces less resistance.

Missing motivation and effort may be another explanation (3) for the fact that some differences between more and less creative persons were found in regard to lesson design task 1 but not to lesson design task 2 . Motivation and also effort may have even decreased from lesson design task 1 to 2 , and even those who may have used the opportunistic procedure for LDT1 may have used the step-by-step procedure for LDT2.

Taking into account these explanations, the probable explanation seems to be that some participants did not use the opportunisic planning procedure but the script- and schema-driven step-by-step procedure, which is the more usual one and requires less effort. As the step-by-step procedure is not a problem solving process but is script- and schema-driven, creativity is not believed to effect lesson designs created by its use. Because no effects of creativity were found in our study with regard to LDT2, it is probable that the participants used this procedure.

As creativity is characterized quantitatively and qualitatively, we not only analyzed the design of one of each participant's lessons with regard to its degree of innovation and its practicability (qualitative aspect of the creativity of lesson designs), we also asked them to design another lesson in order to compare the two designs. We assumed (hypothesis 2) that more creative persons would be able to create more varied lesson designs than less creative persons. We found moderate evidence for this hypothesis: An indepth qualitative analysis shows that the less creative participants used less methods in their two lesson designs and that they were even more similar, whereas the more creative participants used more methods that were even more different from one another. This is moderate evidence for the effect of a creative disposition on the design of lessons.

But a consideration of this explanation has to take into account that, as has been discussed above, it is highly probable that the participants used the step-by-step procedure at least for LDT2. With regard to the results concerning hypothesis 2 this is a limitation because the differences between the two lesson designs of the creative group may have been caused by the use of different procedures for designing lesson 1 and lesson 2, not by the group's creative disposition. This means that hypothesis 2 can not be accepted without restrictions either. Despite these 
limitations, the study gives initial tentative evidence for an effect of a creative disposition on the design of lessons. If this is to be confirmed in further research, it might be necessary to reflect critically on the way teachers are trained. Accordingly, programs for teacher education would have to include creativity training and best practice or worked examples for designing effective lessons. But in order to decide whether this is really going to optimize teacher education, much more research in this field is needed because this study has limitations.

\section{LIMITATIONS AND IMPLICATIONS FOR FURTHER RESEARCH}

This study is limited in several aspects which must be addressed in future research. First, the participants had only 15 minutes time to design each of the two lessons. However, most of them finished earlier. This short amount of time to plan a lesson may have resulted in designs that were different from those that would have been created under less time pressure. It must also be taken into account that this time pressure may have led the participants to not use the opportunistic procedure in planning lessons but rather the script- and schema-driven step-by-step procedure, which is not supposed to result in different lesson designs among more or less creative persons because it is not a problem solving process. Time pressure may also have reduced the effort of the participants in designing the lessons. In future research it would therefore be necessary to give the participants more time for the lesson design tasks. On the other hand, it is not uncommon for teachers doing their everyday job to plan lessons under time pressure.

Second, although the participants of the design experiment were all enrolled as students of Instructional Design, they may not be considered as experts in instructional planning. Accordingly, as novices and experts may not perform identically in instructional planning, the influence of creativity may also be different for expert instructional designers [36-39].

Third, as has been mentioned above, the ability to solve problems is not only a question of a creative disposition but also a question of knowledge. In this study we did not control for the knowledge of the participants concerning lesson designs. As all participants were in the same year of their studies in Instructional Design, we assumed that their knowledge level was similar, but there is no proof for this. In further research it would therefore be good to control for knowledge in order to make sure it is really the creative disposition and not more knowledge that causes creative lesson designs.

Fourth, the small sample size of this study has to be taken into account when discussing the results. For further research it would be better to find bigger samples.

\section{CONCLUSIONS}

As our discussion has emphasized, the study at hand provides moderate evidence for effects of a creative disposition on the ability to design creative lessons. But because of the limitations of this study, it seems reasonable to put more research effort into the question of how creativity correlates with lesson planning. If further evidence for such a correlation may be found, this would have to result in a modification of teacher education programs and maybe even in the way teachers are hired.

\section{ACKNOWLEDGEMENT}

None declared.

\section{CONFLICT OF INTEREST}

\author{
None declared.
}

\section{REFERENCES}

[1] Skinner BF. The science of learning and the art of teaching. Harv Educ Rev 1954; 24: 86-97.

[2] Joyce BR, Harootunian B. Teaching as problem solving. J Teach Educ 1964; 15(4): 420-7.

[3] Landau E. Psychologie der kreativitaet. psychologie und person (Bd. 17). München: Reinhardt 1974.

[4] Preiser S. Kreativitaetsforschung. erträge der forschung. darmstadt: Wissenschaftliche Buchgesellschaft 1986.

[5] Steiner G. Das Planetenmodell der kollaborativen Kreativität. Systemisch-kreatives Problemlösen für komplexe Herausforderungen. Wiesbaden: Gabler 2011.

[6] Parker WC, Gehrke NJ. Learning activities and teachers' decisionmaking: some grounded hypotheses. Am Educ Res J 1986; 23: $227-42$.

[7] Funke J. Psychologie der kreativität. In: Holm-Hadulla RM, Ed. Kreativität 2000; pp. 283-300.

[8] Linneweh K. Kreatives denken: effektive werbung. Karlsruhe: Gitzel 1978.

[9] Schlicksupp H. Innovation, kreativität und ideenfindung. $5^{\text {th }}$ ed. Würzburg: Vogel 1999.

[10] Sternberg JR, Lubart TI. The concept of creativity: prospects and paradigms. In: Sternberg RJ, Ed. Handbook of creativity. 2002; pp. 3-15.

[11] Bromme R. Das Denken von lehrern bei der unterrichtsvorbereitung. eine empirische untersuchung zu kognitiven prozessen von mathematiklehrern. weinheim, Basel: Beltz 1981.

[12] Clark C, Peterson PL. Teachers' thought processes. In: Richardson V, Ed. Handbook of research on teaching. $4^{\text {th }}$ ed. 2001 ; pp. 255 295.

[13] Hacker W. Allgemeine Arbeitspsychologie: psychische Regulation von Wissens-, Denk- und körperlicher Arbeit. $2^{\text {nd }}$ ed. Bern: Huber 2005.

[14] Rothwell WJ, Kazanas HC. Mastering the instructional design process. A systematic approach. San Francisco, CA: Jossey-Bass 1998.

[15] Seel N. Weltwissen und mentale modelle. Göttingen: Hogrefe 1991.

[16] Klafki W. Didaktische Analyse. Hannover: Schroedel 1964.

[17] Blömeke S, Müller C, Felbrich A. Messung des erziehungswissenschaftlichen Wissens angehender Lehrkräfte. In: Blömeke S, Kaiser G, Lehmann R, Eds. Professionelle Kompetenz angehender Lehrerinnen und Lehrer: Wissen, Überzeugungen und Lerngelegenheiten deutscher Mathematikstudierender und ... zur Wirksamkeit der Lehrerausbildung 2008; pp. 172-193.

[18] Borko H, Putnam RT. Learning to teach. In: Berliner DC, Calfee RC, Eds. Handbook of educational psychology New York: Macmillan 1996; pp. 673-708.

[19] Brunner M, Kunter M, Krauss S, et al. Die professionelle Kompetenz von Mathematiklehrkräften - Konzeptualisierung, Erfassung und Bedeutung für den Unterricht. Eine Zwischenbilanz des COACTIV-Projekt. In: Prenzel M, Allolio-Näcke L, Eds. Untersuchungen zur Bildungsqualität von Schule: Abschlussbericht des DFG-Schwerpunktprogramms 2006; pp. 54-82.

[20] Bromme R. Der Lehrer als Experte: Zur Psychologie des professionellen Wissens. Bern: Huber 1992.

[21] Fennema E, Franke M. Teachers' knowledge and its impact. In: Grouws DA, Ed. Handbook of research on mathematics teaching and learning: A project of the National Council of Teachers of Mathematics 1992; pp. 147-64.

[22] Neuweg GH. Das wissen der wissensvermittler. In: Terhart E, Bennewitz H, Rothland M, Eds. Handbuch der Forschung zum Lehrerberuf 2011; pp. 451-77.

[23] Shulman LS. Those who understand: Knowledge growth in teaching. Educ Res 1986; 15(2): 4-14. 
[24] Kuntze S. Zusammenhänge zwischen allgemeinen und situiert erhobenen unterrichtsbezogenen kognitionen und überzeugungen von mathematiklehrkräften. Unterrichtswissenschaft 2008; 36(2): 167-92.

[25] Leuchter M, Pauli C, Reusser, K, Lipowsky F. Unterrichtsbezogene überzeugungen und handlungsleitende kognitionen von lehrpersonen. Zeitschrift für Erziehungswissenschaft 2006; 9(4): $562-79$.

[26] Maggioni L, Parkinson MM. The role of teacher epistemic cognition, epistemic beliefs, and calibration in instruction. Educ Psychol Rev 2008; 20(4): 445-61.

[27] Pajares MF. Teachers' beliefs and educational research: Cleaning up a messy construct. Rev Educ Res 1992; 62(3): 307-32.

[28] Seidel T, Schwindt K, Prenzel M, Rimmele R. Konstruktivistische Überzeugungen von Lehrpersonen: Was bedeuten sie für den Unterricht? In: Meyer MA, Hellekamps S, Prenzel M, Eds. Perspektiven der Didaktik 2009; pp. 259-76.

[29] Pressley M, Roehrig AD, Raphael L, et al. Teaching processes in elementary and secondary education. In: Reynolds WM, Miller GE, Eds. Handbook of psychology: Educational Psychology 2003; vol. 7: pp. 153-75.

[30] Rothland M. Warum entscheiden sich studierende für den lehrerberuf? In: Terhart E, Bennewitz H, Rothland M, Eds. Handbuch der Forschung zum Lehrerberuf 2011; pp. 268-95.
[31] Watt HMG, Richardson PW. Motivational factors influencing teaching as a career choice: development and validation of the FITChoice Scale. J Exp Educ 2007; 75(3): 167-202.

[32] Schoppe KJ. Verbaler kreativitäts-test. Ein verfahren zur erfassung verbal-produktiver kreativitätsmerkmale. Göttingen: Verlag für Psychologie 1975.

[33] Hanke U, Allgaier A. Differences in the use of teaching strategies in different disciplines. In: Henderson JP, Lawrence AD, Eds. Teaching strategies 2011.

[34] Cohen J. A coefficient of agreement for nominal scales. Educ Psychol Measure 1960; 20(1): 37-46.

[35] Landis JR, Koch GG. The measurement of observer agreement for categorical data. Biometrics 1977; 33: 159-74.

[36] Berliner DC, Carter KJ. Differences in processing classroom information by expert and novice teachers. In: Clark CM, Lowyck J, Eds. Teacher thinking and professional action. 1989; pp. 55-34.

[37] Gruber H, Ziegler A. Expertiseforschung. Theoretische und methodische Grundlagen. Opladen: Westdeutscher Verlag 1996.

[38] Kaufman JC, Gentile CA, Baer J. Do gifted student writers and creative writing experts rate creativity the same way? Gifted Child Q 2005; 49(3): 260-70.

[39] Plucker JA, Kaufman JC, Temple JS, Qian M. Do experts and novices evaluate movies the same way? Psychol Market 2009; 26(5): 470-8.

Received: May 18, 2011

Revised: June 27, 2011

Accepted: July 25, 2011

(C) Hanke et al.; Licensee Bentham Open.

This is an open access article licensed under the terms of the Creative Commons Attribution Non-Commercial License (http://creativecommons.org/licenses/by-nc/ $3.0 /$ ) which permits unrestricted, non-commercial use, distribution and reproduction in any medium, provided the work is properly cited. 